\title{
Analysis of Topics of Interdisciplinary Research in the Field of Library Science and Information Science from the Perspective of Altmetrics
}

\author{
Xiaotao Li \\ Library, Nanjing University of Aeronautics and Astronautics, Nanjing, China \\ Email: oshoxiaot@163.com
}

How to cite this paper: Li, X.T. (2021) Analysis of Topics of Interdisciplinary Research in the Field of Library Science and Information Science from the Perspective of Altmetrics. Open Access Library Journal, 8: e8136.

https://doi.org/10.4236/oalib.1108136

Received: October 30, 2021

Accepted: November 13, 2021

Published: November 16, 2021

Copyright $\odot 2021$ by author(s) and Open Access Library Inc.

This work is licensed under the Creative Commons Attribution International License (CC BY 4.0).

http://creativecommons.org/licenses/by/4.0/

\begin{abstract}
On the basis of identifying the interdisciplinary research topics in the field of Library and Information Science, this paper constructed Altmetrics indicator systems and makes SOFM neural network clustering analysis on the comprehensive influence of the research topics, in order to provide reference for the interdisciplinary crossover and integration of Library and Information discipline in China under the background of "New Liberal Arts". The study found that the 20 interdisciplinary research topics could be divided into four types according to their influence composition characteristics: comprehensive hotspots, online social hotspots, academic hotspots, potential hotspots. Interdisciplinary hot topics were important for the intersection and integration of library and information field and other disciplines, and high impact research topics deserved close attention from Chinese scholars.
\end{abstract}

\section{Subject Areas}

Library and Information Science

\section{Keywords}

Altmetrics, Library and Information Science, Interdisciplinary Research

\section{Introduction}

Interdisciplinary research refers to research activities that break down disciplinary barriers and organically integrate theories or methods from different disciplines into one, which is one of the important sources of original scientific achievements [1], and is of great significance in promoting the rapid development of the discipline of Library and Information Science. In 2020, China re- 
leased the "Declaration on the Construction of New Liberal Arts", which strongly advocates interdisciplinary knowledge integration and deep integration, and interdisciplinary cross-fertilization has become a problem that must be faced for the survival and development of the discipline of Library and Information Science [2], and there is an urgent need to promote the development and transformation of the discipline through interdisciplinary research.

Scholars in China have been paying close attention to interdisciplinary research in the field of Library Science \& Information Science since the 1990s [3] [4] [5] [6], and the relevant results have laid a solid foundation for exploring the characteristics and laws of interdisciplinary research, but there is still room for further expansion in the following two aspects: 1) The quantitative characteristics and content characteristics of interdisciplinary research themes in the field of library and information science were not fully revealed; 2) The impact of interdisciplinary research themes in the field of Library Science \& Information Science has not been comprehensively compared and evaluated, and the future development direction of interdisciplinary research needs to be further clarified. Based on the identification of interdisciplinary research themes in the field of Library Science \& Information Science, this study introduces the Altmetrics index system to measure and analyze the comprehensive influence of research themes, with a view to providing reference for the development of China's Library Science \& Information Science discipline in the context of the New Liberal Arts.

\section{Data Sources and Methods}

\subsection{Data Sources}

We searched for research papers in the field of Library Science \& Information Science on the Web of Science (WOS) platform through the "advanced search" function with the search formula "WC = INFORMATION SCIENCE LIBRARY SCIENCE", the type of literature was limited to "Article, Review and Proceedings Paper", and the year was limited to 2016-2020. 25,153 research papers in the field of Library Science \& Information Science were retrieved, and the search period was February 2021.

The common sources of Altmetrics metrics data are ImpactStory, Altmetric.com, Plum Analytics, PLOS ALM and other databases, among which Altmetric.com has the most specific evaluation objects and relatively complete and diverse data sources [7], so this study uses Altmetric.com to collect the Altmetrics metrics data of the papers. The DOI numbers of 25,153 papers exported from the WOS platform were searched in Altmtrics.com, and a total of 12,466 papers with Altmetrics index data were obtained.

The Web of Science platform identifies papers in the "WC" field according to its disciplinary classification system, and each paper belongs to one or more disciplines, and this disciplinary classification system is mostly used in previous studies to determine the disciplinary affiliation of papers [8]. Therefore, this 
study defines papers involving two or more disciplines at the same time as interdisciplinary research papers based on the disciplines marked in this platform. Among 12,466 papers in the field of library and intelligence, a total of 8,541 papers involved both library and intelligence disciplines and other disciplines (including computer science, management, communication, medical informatics, etc.), and the number of interdisciplinary research papers reached $68.51 \%$.

\subsection{Analysis Methodology}

\subsubsection{Interdisciplinary Research Topics Identification}

In this study, we propose to identify research topics from 8541 interdisciplinary research papers. In 2020, CoreVian introduced the "Citation Topics" analysis function in Incites, which uses Leiden University's clustering algorithm to identify topics in the direct citation network of SCI and SSCI papers [9], and constructs a composite topic classification framework system, which can for users to search, identify and analyze topics at three levels: macro (10 topics), meso (326 topics) and micro (2444 topics) [10]. This topic classification system assigns each paper to a single research topic, providing researchers with a stable and reliable way to identify topics. Therefore, in this study, the 8541 retrieved interdisciplinary research papers were imported into Incites to identify each paper's microscopic research theme through its citation theme function.

\subsubsection{Impact Measurement of Interdisciplinary Research Topics}

A normality test of the Altmetrics indicators of the papers revealed that the indicators were not normally distributed, and therefore it is not appropriate to use the arithmetic mean of the indicators to describe the influence of different topics. The rank-sum test was a nonparametric test that did not depend on the specific form of the overall distribution [1] and could be applied without regard to what kind of distribution the subject of study is and whether the distribution is known, so this study measured the influence of the subject of study by calculating the rank mean of each indicator.

The advantage of Self-Organizing Feature Maps (SOFM), also known as Kohoen network, was that the classification results were represented in the competitive layer by self-organizing learning of the input patterns in an unsupervised manner, fully preserving the distributional properties and topology of the input vectors [11]. In this study, the rank mean values of research topics on each Altmetrics metric were imported into Matlab, and the SOFM neural network was built using SOM Toolbox to cluster and analyze the distribution characteristics of multiple Altmetrics metrics for each research topic in order to reveal the influence characteristics of interdisciplinary research topics in depth.

\section{Results and Analysis}

\subsection{Altmetrics Indicators of the Papers}

The descriptive statistics of 17 Altmetrics indicators of 8541 interdisciplinary research papers were shown in Table 1 . In terms of concentration trends, the $75 \%$ 
Table 1. Altmetrics indicators for interdisciplinary research papers in the field of library science \& information science.

\begin{tabular}{|c|c|c|c|c|c|c|c|c|c|c|c|}
\hline \multirow{2}{*}{ Indicators } & \multicolumn{4}{|c|}{ Concentration trends } & \multicolumn{4}{|c|}{ Degree of dispersion } & \multicolumn{2}{|c|}{ Distribution pattern } & \multirow{2}{*}{ Coverage } \\
\hline & $25 \%$ & Median & $75 \%$ & Mean & Min & Max & Range & $\mathrm{Sd}$ & Skewness & Kurtosis & \\
\hline Mendeley & 12 & 25 & 50 & 42.82 & 0 & 2294 & 2294 & 70.93 & 10.95 & 237.16 & $99.08 \%$ \\
\hline Citation & 1 & 3 & 8 & 7.06 & 0 & 790 & 790 & 18.05 & 22.61 & 837.78 & $77.38 \%$ \\
\hline Twitter & 1 & 2 & 7 & 8.85 & 0 & 1188 & 1188 & 29.88 & 16.45 & 441.31 & $76.89 \%$ \\
\hline Facebook & 0 & 0 & 0 & 0.20 & 0 & 17 & 17 & 0.62 & 6.67 & 93.42 & $14.11 \%$ \\
\hline Blog & 0 & 0 & 0 & 0.16 & 0 & 21 & 21 & 0.66 & 10.37 & 198.41 & $9.81 \%$ \\
\hline News & 0 & 0 & 0 & 0.33 & 0 & 148 & 148 & 3.06 & 26.10 & 958.63 & $6.08 \%$ \\
\hline Policy & 0 & 0 & 0 & 0.04 & 0 & 8 & 8 & 0.28 & 11.68 & 213.86 & $3.23 \%$ \\
\hline Google+ & 0 & 0 & 0 & 0.04 & 0 & 15 & 15 & 0.31 & 20.40 & 754.90 & $2.61 \%$ \\
\hline Wikipedia & 0 & 0 & 0 & 0.03 & 0 & 6 & 6 & 0.23 & 13.09 & 236.16 & $1.93 \%$ \\
\hline Reddit & 0 & 0 & 0 & 0.01 & 0 & 4 & 4 & 0.14 & 15.17 & 301.64 & $0.97 \%$ \\
\hline Patent & 0 & 0 & 0 & 0.05 & 0 & 75 & 75 & 1.25 & 49.36 & 2795.32 & $0.70 \%$ \\
\hline Syllabi & 0 & 0 & 0 & 0.25 & 0 & 171 & 171 & 4.15 & 25.54 & 833.13 & $0.66 \%$ \\
\hline Video & 0 & 0 & 0 & 0.00 & 0 & 2 & 2 & 0.05 & 21.38 & 501.16 & $0.26 \%$ \\
\hline Peer review & 0 & 0 & 0 & 0.00 & 0 & 5 & 5 & 0.08 & 42.20 & 2204.05 & $0.23 \%$ \\
\hline Sina Weibo & 0 & 0 & 0 & 0.00 & 0 & 30 & 30 & 0.33 & 91.08 & 8372.89 & $0.12 \%$ \\
\hline F1000 & 0 & 0 & 0 & 0.00 & 0 & 2 & 2 & 0.04 & 37.97 & 1619.78 & $0.09 \%$ \\
\hline Q\&A & 0 & 0 & 0 & 0.00 & 0 & 1 & 1 & 0.03 & 34.89 & 1215.86 & $0.08 \%$ \\
\hline
\end{tabular}

quartiles of most indicators were 0 , and the median was more different from the mean, indicating that the concentration of these indicators was low. In terms of dispersion, the standard deviation of each indicator was much larger than the mean, and the extreme deviation is also larger, indicating that the data dispersion was very high. From the dispersion degree, the standard deviation of each indicator was much larger than the mean value, and the extreme deviation is also larger, indicating that the data were very discrete. In terms of the distribution pattern, the skewness of each indicator was greater than 0 , and the kurtosis is greater than 3, showing a long-tailed right-skewed spike curve. In general, the non-zero scores of most indicators were concentrated in a very small number of literature, which obviously did not obey normal distribution.

The coverage ratio in Table 1 was the ratio of the number of papers with non-zero values under a certain indicator to the total number of papers, which could reflect to some extent the value of the indicator available in the evaluation of papers, and also to see where the influence of papers mainly comes from. The seven indicators with the highest coverage of interdisciplinary research papers in the field of Library Science \& Information Science were, in order, Mendeley readership, Citation, Twitter mentions, Facebook mentions, Blog mentions, News mentions, and Policy mentions. Therefore, these seven indicators were chosen to analyze the influence of interdisciplinary research topics. 


\subsection{Identification of Interdisciplinary Research Topics}

After importing 8541 interdisciplinary research papers into Incites, the micro themes of each paper were identified through the "citation theme" function, and a total of 587 micro themes were obtained, among which the 20 micro themes with the largest number of papers are shown in Table 2. The themes were listed in descending order of the number of papers. The keywords were extracted from 4634 papers for word frequency statistics, and a total of 9312 keywords were obtained, among which 98 high-frequency keywords with a word frequency of 14 or more. In this study, a "topic-high-frequency keyword" (20 rows * 98 columns) matrix was constructed to calculate the TF-IDF value of each high-frequency keyword on each topic, and then the three keywords with the highest TF-IDF values were extracted from each topic to characterize the content of each topic. For example, the main feature keywords of theme 1 "bibliometrics" were Bibliometrics, Altmetrics, and Citation Analysis, and the theme names and feature keywords show a strong consistency, which further verified the reasonableness of "citation themes" in classifying the topics of papers.

Table 2. Interdisciplinary research topics and their keywords.

\begin{tabular}{|c|c|c|c|}
\hline Rank & Research Topics & Papers & Keywords \\
\hline 1 & 6.238.166 Bibliometrics & 1462 & bibliometrics, citation analysis, scientometrics \\
\hline 2 & 4.48.228 Information Literacy & 522 & information behavior, information literacy, information seeking \\
\hline 3 & 6.3.2 Knowledge Management & 471 & $\begin{array}{l}\text { knowledge management, knowledge sharing, information } \\
\text { technology }\end{array}$ \\
\hline 4 & 6.185.184 Journalism & 327 & fake news, digital media, elections \\
\hline 5 & 4.48.672 Sentiment Analysis & 216 & text mining, sentiment analysis, clustering \\
\hline 6 & 1.273.870 Health Literacy & 202 & patient engagement, patient portals, personal health records \\
\hline 7 & 1.14.703 Electronic Health Records & 188 & electronic health record, health information technology, policy \\
\hline 8 & 6.3.368 Technology Acceptance Model & 131 & digital divide, digital inclusion, technology acceptance \\
\hline 9 & 6.3.65 Customer Satisfaction & 128 & social media, content analysis, online communities \\
\hline 10 & 4.48.120 Complex Networks & 128 & social networks, network analysis, scientific collaboration \\
\hline 11 & 6.185.1004 Internet Addiction & 103 & facebook, social capital, social networking sites \\
\hline 12 & 1.54.79 Gene Expression Data & 98 & machine learning, natural language processing, metadata \\
\hline 13 & 6.185.1644 Privacy & 96 & big data, trust, transparency, digital inclusion \\
\hline 14 & 4.48.322 Semantic Web & 89 & ontology, linked data, digital libraries \\
\hline 15 & $\begin{array}{l}\text { 1.155.1378 Null Hypothesis } \\
\text { Significance Testing }\end{array}$ & 88 & open data, data sharing, research data management \\
\hline 16 & 4.48.817 Collaborative Filtering & 85 & personalization, collaborative filtering, recommender systems \\
\hline 17 & 4.17.128 Deep Learning & 78 & deep learning, neural networks, digital libraries \\
\hline 18 & 6.321.2444 Open Government Data & 78 & open data, transparency, open government \\
\hline 19 & 6.288.2155 Digital Humanities & 73 & digital humanities, project management, university libraries \\
\hline 20 & 4.187.2134 Blockchain & 71 & blockchain, security, distributed ledger technology \\
\hline
\end{tabular}




\subsection{Influence of Interdisciplinary Research Topics}

The rank mean values of Altmetrics indicators of the 20 research topics were counted, and the results were shown in Table 3. To further analyze the influence composition characteristics of each research topic, the data of the 7 indicators in Table 3 were imported into Matlab, a matrix of 20 rows and 7 columns was built, and the SOFM neural network was trained with SOM Toolbox: the input layer was set to 7 neurons, corresponding to the 7 research topic influence indicators; the competitive layer is set as a $2 \times 2$ two-dimensional structure, all research topics were classified into 4 categories by 4 neurons. The number of iterations (epochs) was set to 1000 , and the final training results of the SOFM network were shown in Figure 1.

The neurons were represented by blue hexagons in Figure 1, and the neurons corresponding to each of the 20 study topics were labeled. The connection color between neurons indicated the distance: the closer the connection color between neurons was to yellow, the closer the distance between two neurons, the more

Table 3. Rank means of Altmetrics indicators for research topics.

\begin{tabular}{|c|c|c|c|c|c|c|c|c|}
\hline \multirow{2}{*}{ Rank } & \multirow{2}{*}{ Research Topics } & \multicolumn{7}{|c|}{ Rank means } \\
\hline & & Mendeley & Citation & Twitter & Facebook & Blog & News & Policy \\
\hline 1 & Bibliometrics & 2053 & 2376 & 2600 & 2152 & 2427 & 2197 & 2251 \\
\hline 2 & Information Literacy & 1628 & 1730 & 1987 & 2081 & 2161 & 2127 & 2156 \\
\hline 3 & Knowledge Management & 3201 & 2535 & 1459 & 1994 & 2012 & 2150 & 2167 \\
\hline 4 & Journalism & 1940 & 2104 & 2762 & 2650 & 2194 & 2293 & 2205 \\
\hline 5 & Sentiment Analysis & 1919 & 2054 & 1587 & 2006 & 1980 & 2129 & 2144 \\
\hline 6 & Health Literacy & 2564 & 2473 & 2599 & 2679 & 2125 & 2307 & 2450 \\
\hline 7 & Electronic Health Records & 2812 & 2442 & 3032 & 2799 & 2257 & 2564 & 2237 \\
\hline 8 & Technology Acceptance Model & 3006 & 2347 & 1602 & 2032 & 2033 & 2176 & 2177 \\
\hline 9 & Customer Satisfaction & 3085 & 2505 & 1434 & 2102 & 2001 & 2283 & 2161 \\
\hline 10 & Complex Networks & 1497 & 1594 & 1463 & 2068 & 2004 & 2190 & 2144 \\
\hline 11 & Internet Addiction & 2848 & 2624 & 1916 & 2392 & 2184 & 2631 & 2165 \\
\hline 12 & Gene Expression Data & 2364 & 2411 & 2545 & 2586 & 2082 & 2202 & 2144 \\
\hline 13 & Privacy & 2631 & 2115 & 2150 & 2133 & 2169 & 2260 & 2241 \\
\hline 14 & Semantic Web & 1208 & 1299 & 1484 & 2043 & 2105 & 2089 & 2144 \\
\hline 15 & $\begin{array}{c}\text { Null Hypothesis Significance } \\
\text { Testing }\end{array}$ & 2089 & 1997 & 2750 & 2099 & 2385 & 2142 & 2378 \\
\hline 16 & Collaborative Filtering & 1375 & 1610 & 1288 & 1943 & 2059 & 2089 & 2144 \\
\hline 17 & Deep Learning & 1676 & 1654 & 2011 & 2183 & 2002 & 2144 & 2144 \\
\hline 18 & Open Government Data & 2040 & 1925 & 2478 & 2625 & 2007 & 2089 & 2203 \\
\hline 19 & Digital Humanities & 1717 & 1698 & 2769 & 2366 & 2430 & 2207 & 2144 \\
\hline 20 & Blockchain & 3010 & 2596 & 2243 & 2675 & 2345 & 2337 & 2388 \\
\hline
\end{tabular}


similar the influence distribution characteristics of the study topic; the closer the connection color between neurons was to black, the more distant the distance between two neurons, and the more different the influence distribution characteristics of the study topic. The connection between the first neuron and the third neuron was black, which means the influence of the two corresponding research topics was very different; the connection between the first neuron and the second neuron was yellow, which means the influence of the two corresponding research topics was closer.

According to the results of clustering of SOFM network, the influence characteristics of 20 research topics could be divided into 4 categories (see Table 4), namely, comprehensive attention hotspots, online social hotspots, academic research hotspots, and potential attention hotspots.

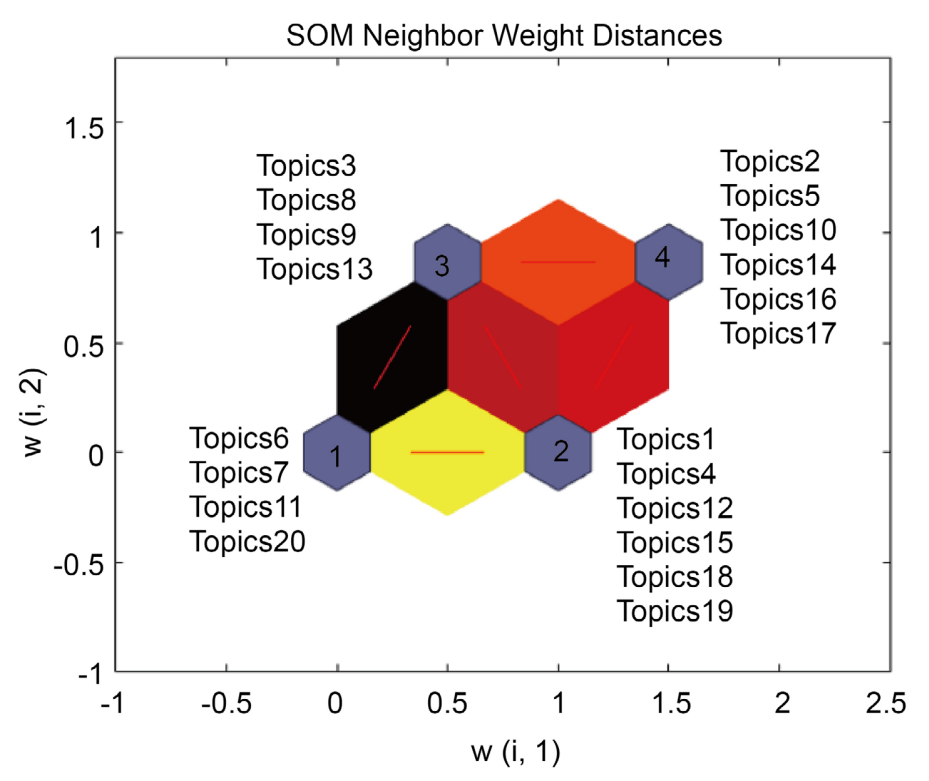

Figure 1. Results of interdisciplinary research topic clustering based on SOFM network.

Table 4. Characteristics of impact distribution of interdisciplinary research themes.

\begin{tabular}{|c|c|c|c|}
\hline Cluster & Characteristics & Research Topics & Main indicators \\
\hline 1 & $\begin{array}{l}\text { comprehensive } \\
\text { hotspots }\end{array}$ & $\begin{array}{c}\text { Topic } 6 \text { Health Literacy, Topic } 7 \text { Electronic Health Records, } \\
\text { Topic } 11 \text { Internet Addiction, Topic } 20 \text { Blockchain }\end{array}$ & $\begin{array}{l}\text { Twitter, Facebook, Blog, News, } \\
\text { Policy, Citation, Mendeley }\end{array}$ \\
\hline 2 & $\begin{array}{l}\text { online social } \\
\text { hotspots }\end{array}$ & $\begin{array}{l}\text { Topic } 1 \text { Bibliometrics, Topic } 4 \text { Journalism, Topic } 12 \text { Gene } \\
\text { Expression Data, Topic } 15 \text { Null Hypothesis Significance Testing, } \\
\text { Topic } 18 \text { Open Government Data, Topic } 19 \text { Digital Humanities }\end{array}$ & Twitter, Facebook, Blog \\
\hline 3 & $\begin{array}{l}\text { academic } \\
\text { hotspots }\end{array}$ & $\begin{array}{c}\text { Topic } 3 \text { Knowledge Management, Topic } 8 \text { Technology Acceptance } \\
\text { Model, Topic } 9 \text { Customer Satisfaction, Topic } 13 \text { Privacy }\end{array}$ & Mendeley, Citation \\
\hline 4 & potential hotspots & $\begin{array}{c}\text { Topic } 2 \text { Information Literacy, Topic } 5 \text { Sentiment Analysis, Topic } 10 \\
\text { Complex Networks, Topic } 14 \text { Semantic Web, Topic } 16 \\
\text { Collaborative Filtering, Topic } 17 \text { Deep Learning }\end{array}$ & Lack of prominent indicators \\
\hline
\end{tabular}




\section{Conclusions}

Interdisciplinary research topics were important grip between the field of $\mathrm{Li}$ brary Science \& Information Science and other disciplines, and were good entry points to enhance the comprehensive influence of the discipline. In the past five years, the interdisciplinary research papers in the field of Library Science \& Information Science have accounted for $68.51 \%$ of the total number of papers in this discipline, and the discipline of Library Science \& Information Science has formed a closer cross-fertilization with computer science, management, communication, medical informatics and other disciplines, forming 20 more concentrated interdisciplinary research themes, which in turn reflect and enhance the influence of this discipline through a series of Altmetrics indicators. These interdisciplinary research topics were reflected and enhanced by a series of Altmetrics indicators.

Seven indicators such as the number of Mendeley readers, Twitter mentions, and Facebook mentions have high coverage in interdisciplinary research papers, indicating that interdisciplinary research results were widely mentioned in academic activities (Mendeley), academic reviews (blogs), social activities (Twitter, Facebook), social media (news), and national policies. The academic influence, social influence, and policy influence of the discipline of Library Science \& Information Science have been significantly reflected and enhanced. This study classifies 20 interdisciplinary research topics into four types according to SOFM network: comprehensive hotspots, online social hotspots, academic hotspots, and potential hotspots, which can provide reference for discipline construction and development of interdisciplinary research in the field of Library Science \& Information Science. The introduction of Altmetrics indicators and the clustering analysis of the comprehensive influence of research topics through SOFM modeling are the innovation of this paper, and these methods can also be extended and applied to other disciplines to further promote the development and deepening of Altmetrics in scientific evaluation. As data of Altmetrics indicators of Chinese papers are difficult to obtain at present, the comprehensive influence and content characteristics of Chinese interdisciplinary research topics are yet to be further explored in the future.

\section{Fund}

This paper was funded by the following two grants: 1) "Methodology and Application of Scientific Research Frontier Identification Based on Altmetrics" (Project No. 19TQC002) of Jiangsu Province Social Science Foundation; 2) "Comprehensive evaluation method and application research based on artificial neural network" (Project No. TSG201701) of Business Innovation Project of Nanjing University of Aeronautics and Astronautics Library.

\section{Conflicts of Interest}

The author declares no conflicts of interest. 


\section{References}

[1] Li, J. (2014) The Concept and Measurement of Interdisciplinarity. Documentation Information Knowledge, 3, 87-93.

[2] Ma, F.C. and Li, Z.Y. (2020) Future Prospect of Library and Information Science in China in the Context of New Liberal Arts. Journal of Library Science in China, 6, 5-16.

[3] Jiang, J. (1995) Interdisciplinary Research in Chinese Librarianship. Journal of Library Science in China, 6, 18-24.

[4] Zhong, X. (2000) Study of Bibliometrics in Interdisciplinary Research of Information Library and Archive Science in China. Journal of the China Society for Scientific and Technical Information, 2, 187-192.

[5] Gong, H.P. and Mei, J. (2020) Research on Knowledge Exchange Dynamics of Library Intelligence Disciplines Based on Interdisciplinary Research. Research on $\mathrm{Li}$ brary Science, 2, 2-11.

[6] Wang, S.M. and Teng, G.Q. (2020) Evolution Analysis on Interdisciplinarity and Differences across Countries in Library and Information Science. Documentation Information Knowledge, 3, 109-118.

[7] Yang, L. and Chen, M. (2015) A Comparative Study of Commonly Used Alternative Metrological Tools. Information Studies: Theory \& Application, 9, 114-119.

[8] Zheng, D.M., Yu, Y.J. and Wen, J.Y. (2020) Characteristics and Evolution of the Trend of Interdisciplinarity in China: An Analysis Based on Web of Science Classifications. Journal of the China Society for Scientific and Technical Information, 8, 872-884.

[9] Traag, V., Waltman, L. and van Eck, N.J. (2019) From Louvain to Leiden: Guaranteeing Well-Connected Communities. Scientific Reports, 1, 1-12. https://doi.org/10.1038/s41598-019-41695-Z

[10] Ian Potter (2020) Introducing Citation Topics in InCites. https://clarivate.com/webofsciencegroup/article/introducing-citation-topics/

[11] Wang, X.C. (2013) MATLAB Neural Networks 43 Case Studies. Beijing University of Aeronautics and Astronautics Press, Beijing. 